\title{
Uma ferramenta digital que faz games educativos: o contexto brasileiro de ensino e aprendizagem
}

\section{A digital tool that makes educational games: the Brazilian context for teaching and learning}

\author{
Patrícia Margarida Farias Coelho \\ Universidade de Santo Amaro (Brasil) \\ Marcos Rogério Martins Costa \\ Universidade de São Paulo (Brasil)
}

\section{Resumo}

Neste estudo, investigaremos os games on-line como emergentes da cultura digital sob uma perspectiva analítica de seus resultados no processo de ensino e aprendizagem. Para isso, apresentamos e discutimos os dados empíricos coletadas por dois relatórios de avaliação (o Projeto Piloto e o Projeto/Pesquisa com os Educadores), fornecidos pelos desenvolvedores de uma ferramenta digital que cria jogos on-line. Esses relatórios são pertinentes como unidades de análise, porque eles avaliam uma ferramenta digital brasileira, FazGame (www. fazgame.com.br), que se utiliza do processo de criação de jogos on-line para inserir, difundir e transformar os objetos de ensino e aprendizagem. Ressaltamos que a FazGame é uma proposta inovadora no cenário educacional brasileiro, porque ela possibilita a criação de jogos aplicados no campo do ensino e aprendizagem. Nossa metodologia consiste em discutir os conceitos teóricos de estudiosos diversos, que se atentaram a potencialidade dos games no ambiente educacional, e apresentar as evidências empíricas dos resultados quantitativos da FazGame apresentados nos dois supracitados relatórios. Os resultados tanto do Relatório de Avaliação do Projeto Piloto do FazGame como do Projeto/Pesquisa com os Educadores indicam que a ferramenta foi bastante apreciada pelos participantes ( $95 \%$ de aceitabilidade), sendo considerada de fácil manuseio, divertida e colaboradora no processo educacional. Por conseguinte, compreendemos, a partir dos dados, que é possível, no contexto brasileiro, aplicar a ferramenta em escolas brasileiras de maneira eficiente e adequada ao contexto institucional-pedagógico.

Palavras-chave: games educativo; teoria; aprendizagem; plataforma digital.

\section{Abstract}

In this study, we investigate the emergence of online games as part of the digital culture (Castells, 2013) and an analytical perspective of their results so far in the process of teaching and learning. For this, we present and discuss the empirical data collected in two evaluation reports (the Pilot Project and the Project/ Research undertaken with teachers), provided 
by the developers of a digital tool that creates online games. These reports are relevant as units of analysis, because they evaluate a Brazilian digital tool, FazGame www.fazgame. com.br), which is used in the creation of online gaming process to insert, disseminate and transform education objects and learning. We observe that FazGame is an innovative proposal in the Brazilian educational scenario, because it enables the creation of games to be applied in the teaching and learning field. Our methodology involves discussing the theoretical concepts proposed by several scholars who pay attention to the potential of games inserted in the educational environment, and present the evidence empirical quantitative results FazGame presented in the two above mentioned reports. The results of both the Evaluation of FazGame's Report Pilot Project and the Project / Research with teachers indicate that the tool was well appreciated by the participants (95\% acceptability) and is considered easy to use, fun and supportive in the educational process. Therefore, we understand from the data that it is possible, in the Brazilian context, to apply the tool in schools efficiently, according to the institutional and pedagogical context.

Keywords: educational games; theory; learning; digital platforms.

Um dos fatos marcantes do século XXI foi o crescimento paulatino das horas reservadas ao lazer nas mais diversas faixas etárias e socioeconômicas em todo o mundo, conforme Coelho e Costa (2013) e Coelho (2012). Dentro desse contexto, os jogos foram sendo inseridos nas práticas humanas com diferentes finalidades. Retomando algumas passagens da história, podemos compreender esse desenvolvimento dos jogos - foco de nosso interesse neste estudo - no cenário da República Federativa do Brasil.

Na segunda metade do século XX no Brasil, jogos eletrônicos, como os de Fliperama e Atari, eram considerados como entretenimento e, em não raros casos, conotados viciosos. Além disso, o acesso a esse tipo de tecnologia era restrito. Isso porque, na década de 1980, era proibida a importação de equipamentos eletrônicos, sobretudo os da área de informática, devido à legislação brasileira vigente. Mesmo com essa política e suas restrições, em maio de 1983 houve, de fato, o lançamento e a venda de um videogame fabricado no território nacional: a Philips começa a vender o videogame Odyssey. No entanto, o videogame de maior sucesso naquele ano foi Atari 2600. Em geral, a política de reserva de mercado afetava, principalmente, os videogames que eram pouco difundidos no território nacional, porque eles eram demasiadamente custosos.

Com a mudança na legislação de comércio e o desenvolvimento das novas tecnologias, o mercado brasileiro de jogos eletrônicos cresceu exponencialmente. Fazendo um cotejo entre 2011 e 2012, podemos perceber esse crescimento. Entre janeiro de 2011 e janeiro de 2012, de acordo com a empresa de consultoria Gfk, as vendas de games aumentaram 149\% devido à redução do preço dos títulos eletrônicos no país. A empresa de consultoria divulgou ainda que, no período supracitado, os preços dos jogos reduziram em torno de $27 \%$. Por exemplo, em janeiro de 2011, um 
jogo eletrônico custava, em média, $\mathrm{R} \$ 200,00$; em 2012, eles estavam em cerca de $\mathrm{R} \$ 170,00$.

Outro fato relevante no universo dos jogos é a crescente queda das vendas dos consoles e portáteis em relação ao aumento das vendas de jogos digitais. A empresa de consultoria Gfk, na pesquisa supracitada, relatou que os jogos on-line representam $32 \%$ do consumo nacional brasileiro. Além disso, ela também registrou uma queda nas vendas de consoles ao redor do mundo, entre 2011 e 2012, de cerca de 13\%, e na venda de portáteis, em torno de $8 \%$. Compreendemos, assim, que os games tendem a ser, cada vez mais, uma nova tecnologia de entretenimento, difundida nas mais diversas áreas de conhecimento e práticas humanas.

Atentos a esse panorama, neste estudo, nosso objetivo é investigar os games online como emergentes da cultura digital (Castells, 2013) sob uma perspectiva analítica de seus resultados no processo de ensino e aprendizagem. Para isso, apresentamos e discutimos os dados empíricos coletadas por dois relatórios de avaliação (o Projeto Piloto e o Projeto/Pesquisa com os Educadores), fornecidos pelos desenvolvedores de uma ferramenta digital que cria jogos on-line - em especial Carla Zeltzer e Antônio Flávio Oliveira Ramos.

Esses relatórios são pertinentes como unidades de análise, porque eles avaliam uma ferramenta digital brasileira, FazGame www.fazgame.com.br , que se utiliza do processo de criação de jogos on-line para inserir, difundir e transformar os objetos de ensino e aprendizagem. Ressaltamos que a FazGame é uma proposta inovadora no cenário educacional brasileiro, porque ela possibilita a criação de jogos aplicados no campo do ensino e aprendizagem (Vygotsky, 1978).

A FazGame é, portanto, uma ferramenta que explora a criatividade e as competências linguísticas, sinestésicas e motoras do usuário-jogador com a finalidade de inserir, difundir e transformar os objetos de ensino e aprendizagem. Ressaltamos que a utilização de games em sala de aula é, ainda, um recurso didático em desenvolvimento no Brasil, por isso a necessidade de maiores estudos sobre essa temática. Neste estudo, observaremos a importância dessa mídia emergente na cultura digital (Castells, 2013). Portanto, entender como os games podem contribuir para a promoção de distintas disciplinas de ensino é o tema que nos interessa discutir neste artigo.

\section{A CULTURA digital E A CRIAÇÃo de GAMES EM SALA DE AULA}

De acordo com Schwartz (2014, p. 17):

A cultura digital promove novas demandas e instaura dinâmicas que desafiam autoridades, controles e medidas de desempenho pessoal, social, educacional e profissional. Essa realidade traz desafios e oportunidades para os professores, caso pretendam cerrar fileiras com seus alunos em defesa de práticas pedagógicas inspiradoras, capazes de ir além da mera transmissão de informações. 
Compreendemos, assim, que houve grandes transformações tecnológicas principalmente nas últimas cinco décadas. $\mathrm{O}$ desenvolvimento da internet foi e continua sendo um grande propulsor e difusor dessas mudanças que criam novas tecnologias e, com elas e a partir delas, novas competências e habilidades na sociedade humana.

De acordo com Castells (2013), a sociedade como um todo se modificou na passagem do século XX para o XXI. Há uma transformação cada vez mais forte do modelo taylorista-fordista, que fora dominante principalmente nas primeiras revoluções industriais. Torna-se necessário e mais desejável um modelo de especialização flexível em que o processo de troca e transmissão de conhecimento não seja seriado e monolítico em cada etapa, mas seja contínuo, adaptativo e dinâmico. Essa é a ideia de uma sociedade em rede, de acordo com Castells (2013). Dessa forma, a cultura digital emergente no século XXI caracteriza-se como uma sociedade globalizada e altamente informatizada, na qual o conhecimento é privilegiado como fonte de valor e também de poder (Castells, 2013; Foucault, 1979).

Dentro dessa sociedade digital, vem se proliferando a importância da utilização dos games em ambiente escolar. Essa proposta de utilizar jogos em sala de aula vem provocando muitos debates. Eguia-Gomez, Contreras-Espinosa e Solano-Albajes (2012, p. 131) explicam que:

videogames podem ser utilizados para adquirir novos conhecimentos, pois os jogos possuem a função de comunicar e persuadir. [...] os videogames despertam o interesse do aluno para uma autoaprendizagem estimulando através de seu uso o hábito para busca do conhecimento [...] o professor como o mediador do conteúdo, porém, não é somente o professor um dos responsáveis pelo êxito do videogames em sala de aula, a escola deve também colaborar com a utilização dos jogos em sala de aula reconhecendo esse novo potencial pedagógico. Escola e professor juntos devem estabelecer uma dinâmica que reconheçam que a utilização de videogames em sala de aula é uma mudança e avanço no processo pedagógico. Utilizar os jogos de forma a auxiliar a aprendizagem significa reorganizar os modelos organizacionais e compreender que atualmente os videogames são uma nova ferramenta educativa que funciona e alcança excelentes resultados.

Embora haja distintos pontos de vista sobre a potencialidade do uso de jogos em sala de aula, ressaltamos que existem bons resultados da aplicabilidade dos games na escola. Dessa forma, os jogos funcionam como um adjuvante nas práticas educacionais, pois, de forma geral, a criação de jogos digitais estimula uma compreensão e aprendizagem mais ativa dos participantes. Conforme Kapp (2012), o uso dos games "envolve pessoas, motiva a ação, promove a aprendizagem e resolve problemas". Logo, a criação de jogos digitais pode auxiliar a transpor métodos de ensino e aprendizagem para a educação formal. Isso já era previsto há trinta anos para as novas tecnologias que estavam surgindo. Como, por exemplo, Papert (2008) 
que considerava os métodos educacionais criados com o auxílio de novos expedientes tecnológicos mais "rápidos, muito atraentes e gratificantes" (p. 20).

Assim, pontuar a importância e relevância de se criar games em sala de aula possibilita compreendermos a estrutura de um jogo - apresentação, desafio, fase, recompensa, etc., - e verificarmos as potencialidades do game como uma ferramenta didática que pode ser utilizada em diferentes disciplinas para desenvolver habilidades e competências dos participantes desse processo de ensino e aprendizagem.

\section{O PROCESSO DE ENSINO E APRENDIZAGEM E A FERRAMENTA DIGITAL FAZGAME}

Há, no cenário brasileiro, diversas discussões sobre o que é ensino e como se faz. Destacamos, também, que existem distintas propostas teóricas e escolas que se debruçam sobre o processo de aprendizagem. Dentre as várias definições, ancoramonos em Scheffler (1973) para determinar o ato de ensinar, pois, segundo esse estudioso, temos que nos atentar à integridade intelectual do aluno que participa ativamente do processo de ensino e aprendizagem: "ensinar pode ser caracterizado como uma atividade que visa promover a aprendizagem e que é praticada de modo a respeitar a integridade intelectual do aluno e a sua capacidade para julgar de modo independente" (Scheffler, 1973, p. 67).

Entendemos, assim, que as modificações socioculturais decorrentes em qualquer contexto são permeadas por um conjunto de práticas individuais e também coletivas que são ensinadas e aprendidas independentemente do meio escolar. Isso é possível, porque o aprendiz participa ativamente do processo de ensino e aprendizagem com sua própria estrutura cognitiva, que também é sociointeracional.

Essa reflexão se sustenta a partir da teoria construtivista fundada por Vygotsky (1978) e Ausubel (1968). Segundo esses autores, aprendemos quando construímos a nossa própria estrutura cognitiva. Essa postura teórica rompe com a perspectiva behaviorista que apregoava que aprendíamos pelo estímulo-resposta, principalmente pela memorização. Segundo Vygotsky (1988), para o processo de ensino e aprendizagem se efetuar, é necessário que a aprendizagem seja significativa. Para tanto, a aprendizagem deve estimular:

a. Uma disposição do aluno para apre(e)nder o novo conteúdo;

b. Uma base de informações que sirva como material de apoio durante o processo;

c. O papel do professor como um facilitador de transmissão, transformação e geração de objetos de saber.

Esses pressupostos teóricos da teoria construtivista se tornam ainda mais relevantes no contexto do século XXI, porque temos uma nova geração, constituída por pessoas nascidas entre as décadas de 1980 e 1990 que possuem características 
singulares, segundo Prensky (2006). Essa geração é conhecida como Geração Y, composta por nativos digitais. Coelho (2012, p. 3) explica que:

Os nativos digitais, segundo Prensky (2001), possuem a capacidade de realizar múltiplas tarefas, o que representa uma das características principais dessa geração. Ainda segundo esse autor, essa nova geração é formada, especialmente, por indivíduos que não se amedrontam diante dos desafios expostos pelas Tecnologias da Informação e da Comunicação (TIC) e experimentam e vivenciam múltiplas possibilidades oferecidas por novos aparatos digitais. Portanto, esse fascínio característico da Geração Y pela descoberta e experimentação deve ser explorado pela escola, de forma a direcioná-la para um ensino e uma aprendizagem que dialoguem e interajam com os novos meios tecnológicos.

Desse modo, temos tanto nativos digitais quanto imigrantes digitais, conforme propõe Prensky (2006). Os nativos digitais são aqueles que já nasceram na era da tecnologia digital, enquanto que os imigrantes digitais são aqueles que nasceram na era analógica, tendo, posteriormente, migrado para o mundo digital, em geral, na fase adulta. Como esses dois grupos tiveram experiências e vivências diferentes com o universo digital, eles pensam e processam informações de maneira distinta, embora possam utilizar os mesmos aparatos tecnológicos, conforme Prensky (2012).

Além disso, temos que levar em conta que existem estilos de aprendizagem distintos e inteligências múltiplas. Mattar (2013) explica os estilos de aprendizagem e as inteligências múltiplas, a partir dos estudos do psicólogo norte-americano Howard Gardner:

Da mesma maneira que possuímos estilos de aprendizagem distintos, possuímos inteligências distintas. [...] Estilo e inteligência são fundamentalmente diferentes tipos de construtos psicológicos. Estilos referem-se à forma habitual com que um indivíduo aborda uma gama de materiais - por exemplo, um estilo brincalhão ou um estilo mais sério. A inteligência, por sua vez, refere-se ao poder computacional de um sistema mental: por exemplo, uma pessoa cuja inteligência linguística é forte é capaz de calcular prontamente a informação que envolve linguagem (Mattar, 2013, p. 8).

Compreendendo a aprendizagem significativa (Vygotsky, 1978; 1988; Ausubel, 1968), as novas competências dos nativos digitais (Coelho, 2012; Prensky, 2006; 2012) e os estilos de aprendizagem e as inteligências múltiplas (Mattar, 2013), podemos dizer que é necessário desenvolver e estimular novas ferramentas que auxiliem no processo de ensino e aprendizagem. Por isso cada vez mais os jogos são inseridos no contexto escolar, em especial os games digitais. Eguia-Gomez, Contreras-Espinosa e Solano-Albajes (2012, p. 121) explicam a importância dessa inserção e de seu estudo:

O uso de games digitais na aprendizagem é atualmente um importante foco de estudo, pois permite novas possibilidades de interação com o ambiente e facilitam a 
introdução da tecnologia da informação, a comunicação e a experimentação (Hayes, 2007) de uma narrativa viva que permite a construção de uma realidade através de narração de histórias e de recursos cognitivos básicos pelos quais os seres humanos conhecem o mundo [...].

Destacamos, ainda, que existem diversas definições para o conceito de jogo. A partir de Huizinga (2013) e Caillois (2001), podemos dizer que os jogos são ambientes que proporcionam uma liberdade de ação limitada, pois há a necessidade de definir metas e objetivos que visam levar o jogador a avançar em determinadas etapas de um percurso. Esse processo ajuda na tomada de decisões e também no desenvolvimento de responsabilidades, contribuindo, portanto, para o crescimento pessoal do aluno-jogador, no caso dos jogos educativos produzidos pelo FazGame (www.fazgame.com.br).

FazGame "é uma ferramenta de colaboração para autoria de games educacionais por alunos e professores do Ensino Básico" (FazGame, 2013a). É, portanto, uma ferramenta pioneira no panorama brasileiro para o desenvolvimento da Educação, estimulando o processo de ensino e aprendizagem no contexto do século XXI. O objetivo dessa ferramenta é possibilitar que professores e alunos gerem conhecimento em conjunto, na medida em que eles construam jogos motivadores de aprendizagem. De acordo com os desenvolvedores dessa ferramenta, os jogos produzidos no FazGame são compostos de, pelo menos: (a) um desafio; (b) algumas metas de aprendizagem (indicadores) e (c) uma história interessante, que conecta o desafio às metas de aprendizagem.

Salientamos ainda que o projeto piloto do FazGame foi realizado em parceria com a Secretaria Municipal de Educação do Rio de Janeiro e com o Núcleo de Tecnologia do Município do Rio de Janeiro (NTM) e o Projeto/Pesquisa com Educadores foi realizado pelos professores de escolas primárias do Rio de JaneiroRJ. Os idealizadores do FazGame e desses relatórios são Carla Zeltzer e Antônio Flávio Oliveira Ramos, os quais contaram ainda com o apoio da equipe do NTM e com os professores das turmas do Projeto Nenhum Jovem a Menos (NJM).

Observamos, assim, que a ferramenta FazGame constitui um objeto de estudo pertinente para analisarmos como se realiza um projeto de criação e desenvolvimento de games no âmbito da Educação, dentro do processo de ensino e aprendizagem no território brasileiro.

\section{METODOLOGIA}

Em termos metodológicos, este trabalho pode ser caracterizado como descritivo, uma vez que busca evidenciar determinado fenômeno (criação de jogos digitais aplicados ao processo de ensino e aprendizagem) a partir da descrição de um objeto (ferramenta FazGame). Conforme explica Gil (2013), uma pesquisa descritiva objetiva a descrição das características de determinadas população ou fenômeno, utilizandose, para isso, de técnicas padronizadas de coleta de dados, como, por exemplo, o 
questionário e a observação sistemática - métodos esses que foram aplicados para a obtenção dos dados nos relatórios que trataremos nos próximos tópicos.

Os dados que discutiremos foram coletados e padronizados por dois relatórios, a saber: (i) Avaliação do Projeto Piloto do FazGame (doravante RAPPFazGame) e do (ii) Projeto/Pesquisa com os educadores (doravante PPE), ambas as pesquisas realizadas em 2013, e cedidos pelos seus desenvolvedores Carla Zeltzer e Antônio Flávio Oliveira Ramos à nossa pesquisa. Esses relatórios e suas discussões foram embasados em um método quantitativo. Isso porque utilizou-se um questionário que, após ter suas respostas tabuladas em gráficos, foi analisado usando-se técnicas estatísticas, buscando-se, assim, traduzir em números, as opiniões e as informações dos participantes da pesquisa.

O RAPPFazGame e o PPE se embasaram na Oficina FazGame que foi realizada com 22 alunos do Projeto NJM, com idades entre 13 e 16 anos, nos meses de outubro e novembro de 2013. Participaram também dessa oficina organizando os alunos: um pesquisador, um professor, dois coordenadores tecnológicos e um consultor pedagógico. Ressaltamos que os alunos se reuniram em cinco grupos, para realizar a Oficina. Elas eram compostas pelas seguintes etapas, conforme o documento supracitado:

1. Contextualização dos games como entretenimento/ferramenta educacional e criação da história inserida no FazGame;

2. Criação do game no FazGame - adaptação da história ao contexto atual da ferramenta;

3. Testes e avaliação dos games criados, do FazGame e do processo educacional (FazGame, 2013a, p. 1).

No próximo tópico, discutiremos, a partir dos relatórios supracitados, as experiências e vivências dos encontros realizados durante a Oficina FazGame.

\section{EXPERIÊNCIAS E VIVÊNCIAS DA OFICINA FazGame}

De acordo com o RAPPFazGame (2013a, pp. 1-2), no primeiro encontro, houve as seguintes atividades:

No primeiro encontro trabalhamos com os alunos a estrutura dos games e as semelhanças e diferenças entre um game criado para diversão e um game educacional. Também discutimos qual o aprendizado oriundo de jogar games, onde citamos itens como desenvolvimento da concentração, perseverança e estratégia para vencer os desafios propostos pelos games. Neste encontro, validamos que os games têm um importante papel no cotidiano dos jovens, que pode ser adequadamente aproveitado no ambiente educacional, sendo esta a proposta do FazGame. 
Conforme consta no RAPPFazGame (2013a, p. 2), entre o segundo e terceiro encontro, as seguintes atividades foram desenvolvidas:

No $2^{\circ}$ e no $3^{\circ}$ encontros discutimos os componentes de um game point and click no formato de missões:

- A estrutura de missões, fases e objetivos;

- Os cenários, personagens e objetos que compõem o enredo do game.

Também falamos sobre os conteúdos de aprendizagem (o que se quer ensinar com o game), discutindo estratégias para associar o conteúdo à história do game de forma interessante.

Com essa base, os alunos criaram suas histórias, e contaram com o apoio de seus professores para refiná-las durante o horário escolar.

Segundo o RAPPFazGame (2013a, p. 2), no terceiro encontro, desenvolveram-se as seguintes atividades específicas:

No $3^{\mathrm{o}}$ encontro, os alunos conheceram a ferramenta FazGame, e puderam experimentar suas funcionalidades de forma livre, criando pequenos games. Ao final desse encontro, todos sabiam utilizar o FazGame para criar suas histórias, o que validou o objetivo de criar uma ferramenta de simples uso. figura:

Podemos observar a tela principal da ferramenta digital FazGame na seguinte

Figura 1. Tela inicial da configuração do game

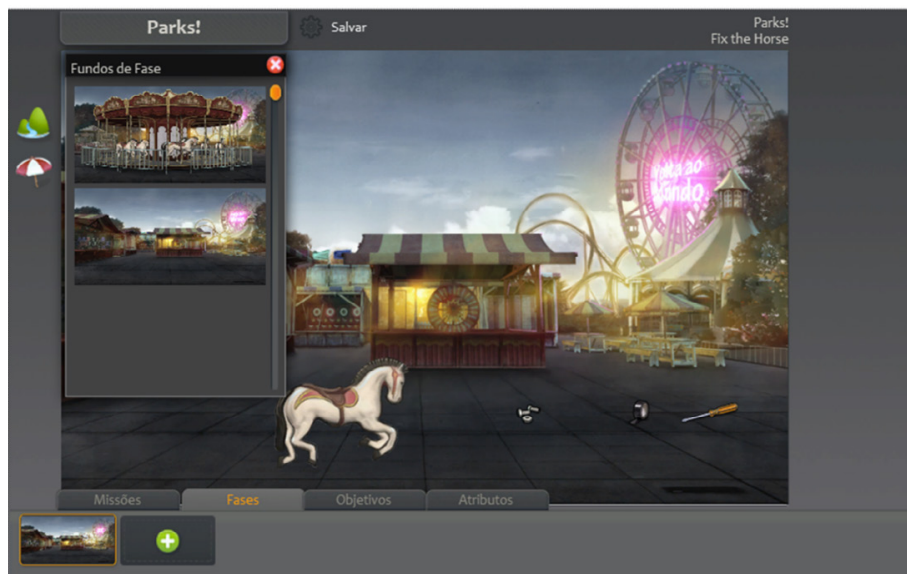

Fonte: RAPPFazGame (2013a, p. 2) 
Entre o quarto e quinto encontro, os alunos fizeram as seguintes atividades, de acordo com RAPPFazGame (2013a, p. 2):

No $4^{\mathrm{o}}$ e no $5^{\mathrm{o}}$ encontros, os alunos trabalharam no FazGame, inserindo suas histórias. Na medida em que evoluíam no processo, percebiam itens a serem incluídos nas histórias e encadeamentos necessários, trabalhando a escrita criativa e o raciocínio lógico - duas habilidades essenciais. Ao trabalharem em grupo, também desenvolveram essa importante habilidade, complementando suas competências para realizar o projeto de criação do game.

Os jogos criados durante esses encontros tiveram um ou dois objetivos construídos para estimular o desenvolvimento das ações do game. Na figura 2, a seguir, podemos observar a construção de um objetivo realizada por um dos grupos:

Figura 2. Tela principal da configuração do game

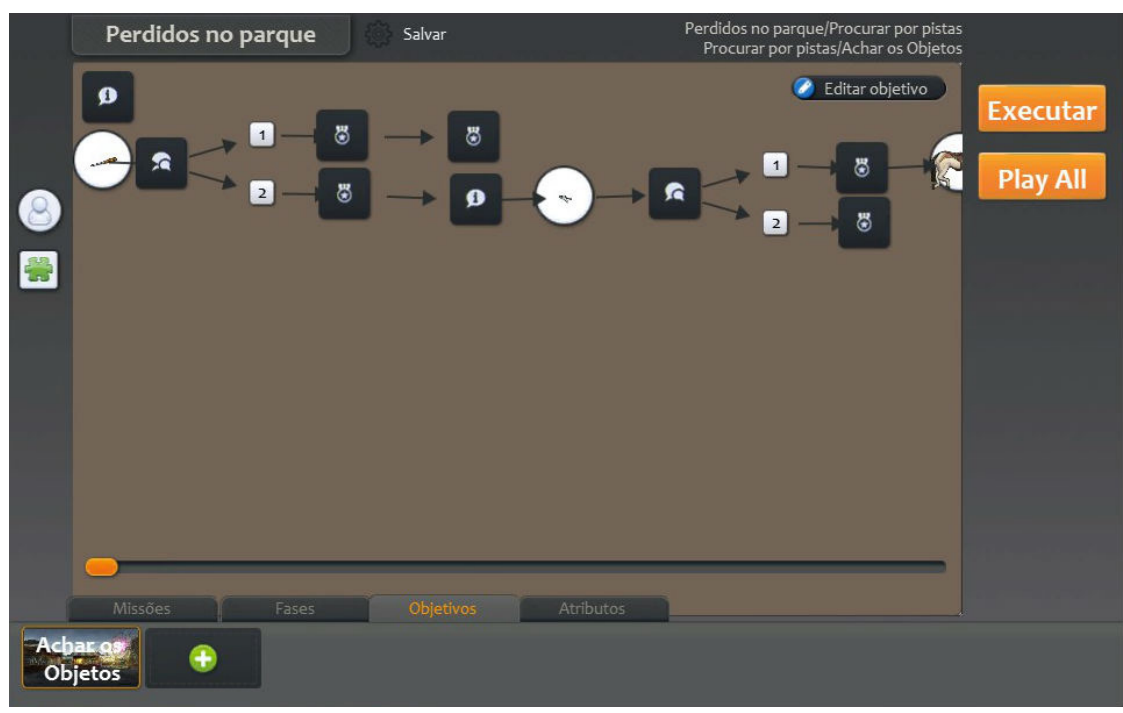

Fonte: RAPPFazGame (2013a, p. 4)

Segundo RAPPFazGame (2013a, p. 4), nessa versão da oficina, a ferramenta FazGame contava com os seguintes recursos:

- Mensagens e diálogos entre os personagens;

- Perguntas com várias respostas possíveis; 
- Recompensas - para pontuação dos objetivos de aprendizagem e de bônus extras;

- Click nos objetos do cenário.

A partir desses recursos, os grupos criaram o enredo e a lógica de seus jogos, encadeando as fases e etapas. De acordo com RAPPFazGame (2013a, p. 4), essa oficina "envolveu um aprendizado sobre as seguintes habilidades/ processos: planejamento, organização do grupo e atividades, revisão e melhoria do produto criado (no nosso caso, o game)".

Criados os jogos no FazGame, no último encontro, os grupos utilizaram os seus próprios games. A seguir, foi feita uma discussão sobre o aprendizado durante os encontros da oficina, além de uma avaliação formal, feita por meio de um questionário. As respostas desse questionário foram padronizadas em gráficos, os quais foram vertidos em língua inglesa para maior divulgação dos resultados, principalmente em âmbito internacional, pelos seus idealizadores. Por isso, na discussão dos resultados no tópico a seguir iremos adotar os gráficos de forma original, isto é, apresentá-losemos em língua inglesa.

\title{
ANÁLISE DOS RESULTADOS E DISCUSSÃo
}

\author{
No RAPPFazGame (2013a, p. 5), consta que:
}

Ao adaptar suas histórias para o formato de um game, os alunos puderam experimentar a criação de narrativas não lineares, onde ações podem ser disparadas por uma condição específica (causalidade) e várias ações podem ocorrer simultaneamente. Envolvendo o raciocínio lógico para criar os encadeamentos necessários e a sequência de suas histórias.

Esse modo de construção da narrativa difundido na ferramenta FazGame evidencia, com primazia, a necessidade de se compreender as novas urgências trazidas pelo meio digital. Como reflete Coelho (2012), isso é uma demanda necessária e um desafio para os pesquisadores atuais:

Talvez o maior desafio para os pesquisadores atuais seja pensar e refletir sobre as novas urgências trazidas pelo meio digital e reformular os paradigmas tradicionais, visto as novas indagações. O próprio universo digital clama por vocábulos e compreensões que lhe sejam próprios. Não adianta enclausurar essas novas potencialidades trazidas pelo meio digital dentro dos padrões de comunicação de massa. Um bom exemplo é o conceito de narrativa, no qual muitos dirigiram seu olhar para tentar definir e explicá-lo. Talvez o maior equívoco realizado por alguns pesquisadores foi tentar pensar a narrativa digital a partir dos conceitos e teorias já existentes ao invés de criar novos conceitos. Dependendo da área e linha do pesquisador, este buscava moldurar a narrativa digital em sua teoria para assim explicá-la, mas o que propomos fazer 
vai contra a esse raciocínio, pois buscamos nos ancorar em autores que pensaram os meios digitais em suas especificidades e que criaram vocábulos próprios para os novos conceitos emergentes desse meio (p. 171).

Além dos desenvolvimentos dessas habilidades na construção da narrativa, segundo o RAPPFazGame (2013a, p. 6), os alunos identificaram que aprenderam:

- Como criar games;

- O trabalho em equipe;

- O conteúdo pedagógico dos jogos que criamos;

- Como usar FazGame.

Destacamos que, em conformidade com a RAPPFazGame (2013a), uma das diferenças percebidas pelos alunos foi aprender de forma lúdica:

Os alunos perceberam a diferença de "aprender de forma divertida", e foi o que mais os atraiu na Oficina FazGame. Esta informação foi confirmada na avaliação formal, onde $95 \%$ dos alunos disseram que gostariam de fazer outra Oficina FazGame (sendo que 80\% gostariam de ter uma Oficina FazGame todo ano) (FazGame, 2013a, p. 5).

Esses dados são reiterados pelos resultados do outro relatório, o PPE, como podemos observar nas figuras a seguir:

Figura 3. As escolas utilizarão o FazGame?

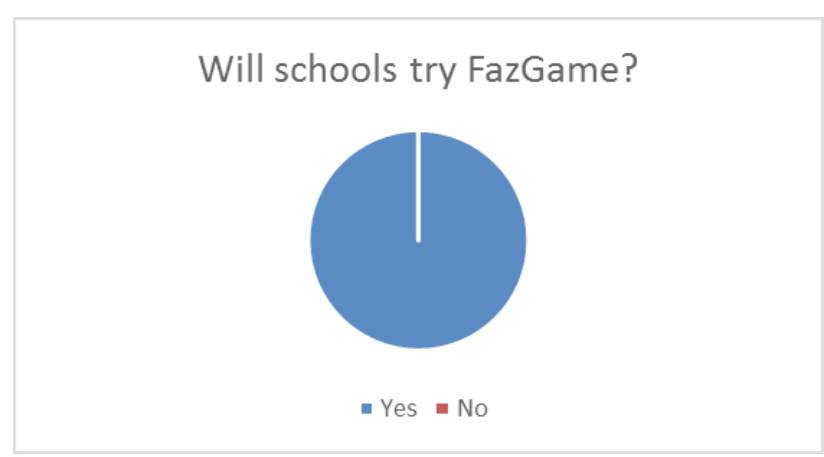

Fonte: PPE (2013b) 
Figura 4. Você gostaria de participar outra vez da Oficina FazGame?

\section{Would you like to participate in another FazGame WorkShop?}

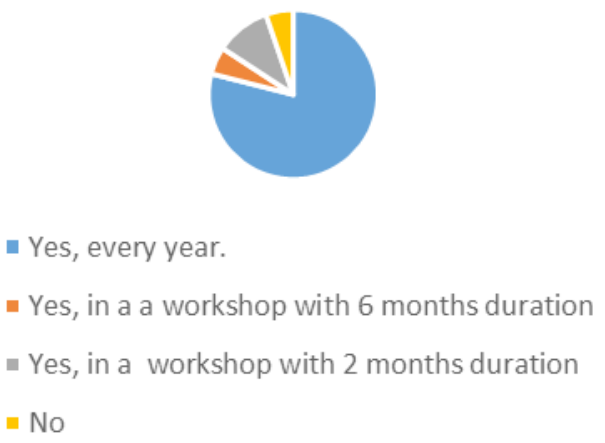

Fonte: PPE (2013b)

Conforme RAPPFazGame (2013a, p. 5), a percepção sobre o uso do FazGame no ambiente escolar:

Quanto à percepção sobre o uso do FazGame no ambiente escolar, mais de $75 \%$ dos alunos identificaram na avaliação formal o FazGame como uma ferramenta que motiva para o aprendizado e desenvolve a competência de colaboração.

Como resultado da avaliação formal e discussões, verificamos que os alunos não se apropriaram plenamente do conceito de "criar conhecimento". Visto que historicamente a escola é vista pelos alunos com uma estrutura rígida onde eles "recebem conhecimento", é esperado que essa mudança de percepção ocorra de forma gradual. O FazGame foi concebido para facilitar este processo.

Essa facilidade é percebida também no próprio manuseio da ferramenta FazGame, já que a maioria dos alunos a considerou de uso muito fácil, como podemos apreender na figura 5. Já na figura 6, a partir do PPE, podemos observar maiores informações sobre a percepção do uso do FazGame no ambiente escolar: 
Figura 5. O FazGame é fácil de usar?

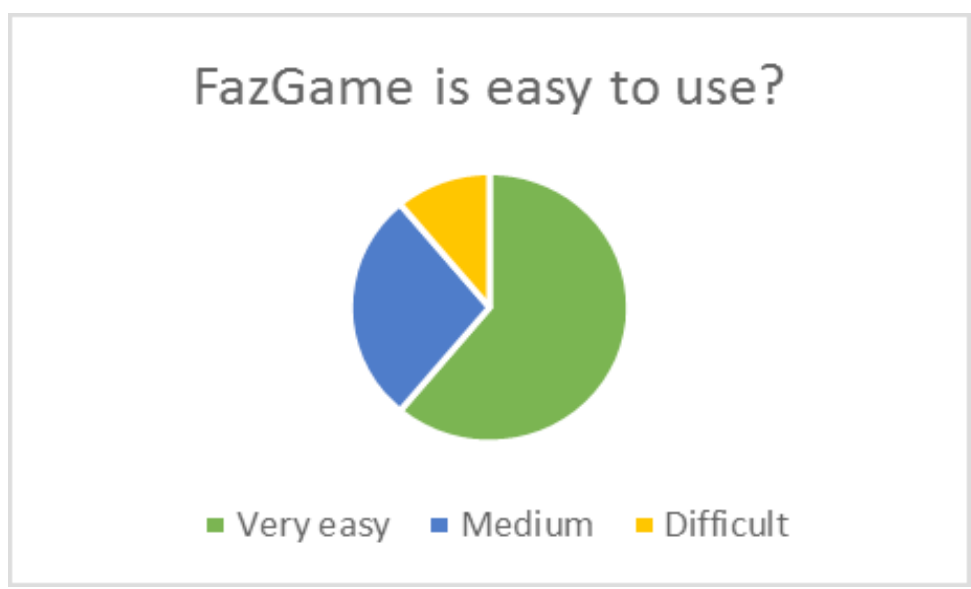

Fonte: PPE (2013b)

Figura 6. Contribuições para o ambiente escolar

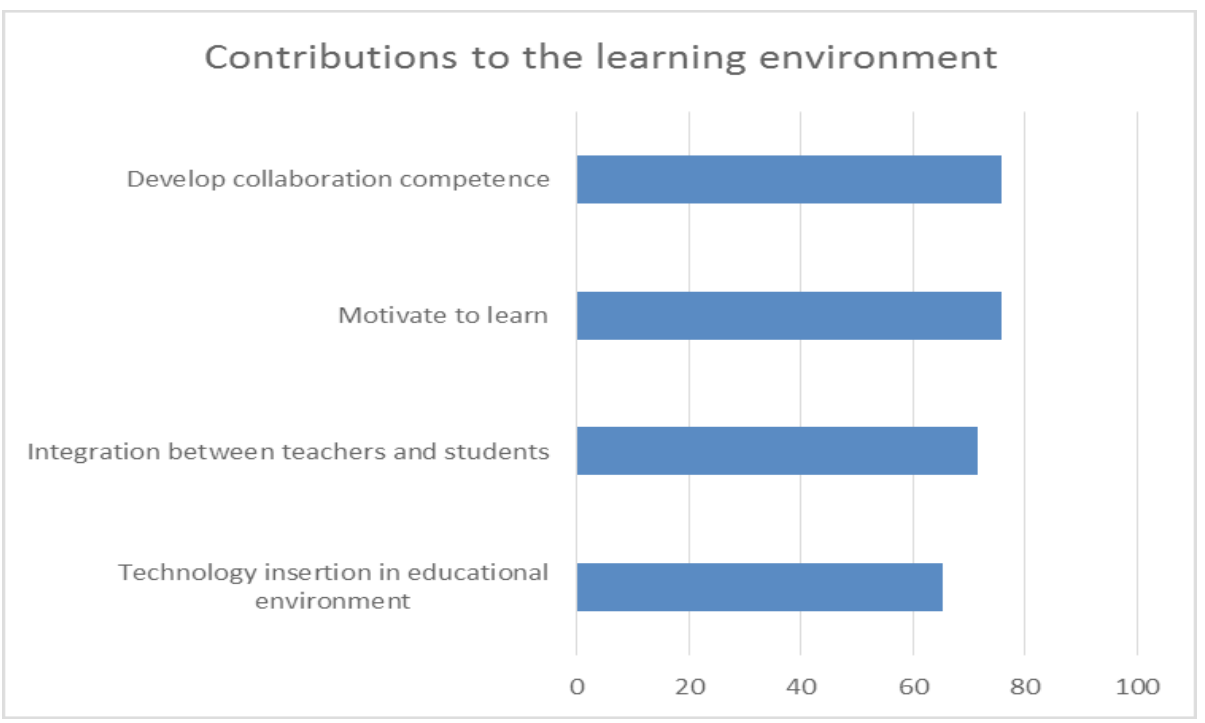

Fonte: PPE (2013b)

No PPE, são apresentadas algumas barreiras identificadas durante o processo de inserção e desenvolvimento da Oficina pelos educadores, a saber: 
- Infraestrutura precária (computadores, acesso à Internet);

- Medo do professor sobre a tecnologia, a formação dos professores;

- Dificuldade de adoção de novas práticas e processos pedagógicos pelas escolas (FazGame, 2013a, p. 6).

Além disso, quando perguntados - tanto aos educadores, quanto aos alunos - como o FazGame poderia ser adotado nas escolas, todos responderam que essa ferramenta ajudaria no ensino específico ou em tópicos mais complexos e elaborados, uma vez que os games educativos estimulam os estudantes a aprenderem de maneira não-linear, dinâmica e adaptativa (Coelho, 2012; Mattar, 2013; Prensky, 2012; 2006). Podemos observar esses dados na figura a seguir:

Figura 7. Como o FazGame poderá ser adotado pelas escolas?

\section{How will FazGame be adopted by schools?}

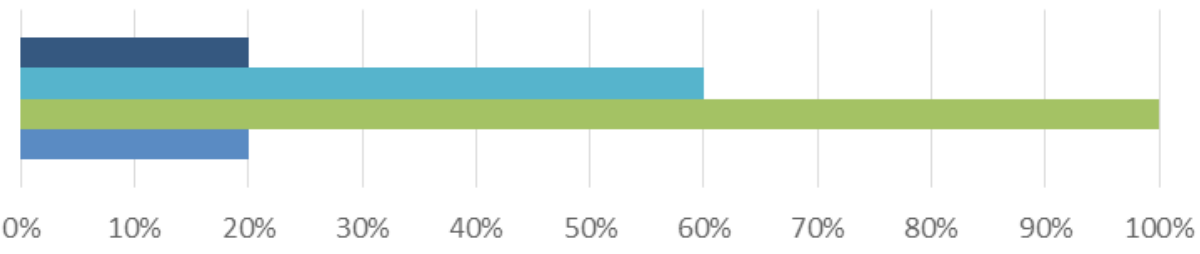

FazGame will be used as an extra-class activity

- Teachers will use FazGame periodically throughout the year

- Teachers will use FazGame to teach specific/difficult subjects, where games can motivate students to learn

- Teachers will use FazGame once in a year, as a school work

\section{Fonte: PPE (2013b)}

No Projeto Piloto com os Educadores (2013b), já consta que há a necessidade de algumas melhorias para o progresso e uso do projeto FazGame, seja como oficina, seja como ferramenta digital:

Como pontos de melhoria da ferramenta, a maior parte dos alunos citou a criação de mais cenários, personagens e objetos. Essa resposta era esperada pela equipe do FazGame, pois, por se tratar de um projeto piloto, esses itens encontram-se em 
desenvolvimento. A expansão da biblioteca gráfica do FazGame é um fator muito importante para que os alunos possam exercer sua criatividade ao criar seus games.

Um outro ponto de melhoria no processo é a formação dos professores, anterior à realização de Oficinas FazGame. Devido ao cronograma de desenvolvimento do FazGame para o projeto piloto, não foi possível incluir essa atividade (FazGame; 2013a, p. 5).

Esses dados coletados e discutidos no RAPPFazGame (2013a) e no PPE (2013b) demonstram que a ferramenta colaborativa FazGame é um instrumento de criação de games muito eficaz no processo de ensino e aprendizagem, seja pela grande aceitabilidade dos alunos-jogadores, seja pelas novas competências e habilidades que são desenvolvidas e estimuladas durante o processo de criação de um jogo.

\section{CONSIDERAÇÕES FINAIS}

Os resultados dos dois relatórios discutidos (FazGame, 2013a; 2013b) demonstraram que é possível utilizar os games - dentro dos termos aqui definidos - aplicados ao campo da Educação. Ressaltamos que o projeto FazGame continua em progresso e, como ferramenta, concretiza-se como um instrumento didático eficiente e adequado à Geração $\mathrm{Y}$, dos nativos digitais, bem como aos dos imigrantes digitais (Mattar, 2013; Prensky, 2006). Por conseguinte, aplicar a proposta de criação e desenvolvimento de games aplicados a Educação é uma proposta válida e que, em pouco tempo, tenderá a ser crucial para o desenvolvimento das capacidades e competências do aprendiz, consolidando, assim, cada vez mais a aprendizagem significativa, proposta por Vygotsky (1978) e Ausubel (1968).

Já podemos vislumbrar isso nas próprias considerações do relatório RAPPFazGame (2013a) que assevera: "Vimos que, como todo o aprendizado, o uso do FazGame também acontece de forma incremental, sendo que esperamos que ao participar de várias oficinas FazGame, os alunos passem a criar histórias e games cada vez mais elaborados".

Esse projeto é precursor no panorama educacional brasileiro, pois, nas escolas do território nacional, o ensino e a aprendizagem, ainda, continuam enrijecidos em sua didática e metodologia. Por isso as escolas, ao utilizarem a ferramenta colaborativa do FazGame, deve envolver toda a equipe pedagógica nesse processo que exige diferentes e diversas competências e habilidades: trabalhar em equipe, construir narrativa não-linear, estimular a criatividade; dominar as novas tecnologias da comunicação e da informação, dentre outras. Logo, os games evoluem seja dentro ou fora do contexto escolar. 


\section{REFERÊNCIAS BIBLIOGRÁFICAS}

Ausubel, D. P. (1998). Educational psychology: a cognitive view. New York: Rinehart and Wiston.

Caillois, R. (2001). Os jogos e os homens: a máscara e a vertigem. Trad. José Garcez Palha. Lisboa: Cotovia.

Castells, M. (2013). A sociedade em rede. Trad. Roneide Venâncio Majer. São Paulo: Paz e Terra.

Coelho, P. M. F. (2012). Os nativos digitais e novas competências tecnológicas. Texto livre: Linguagem e tecnologia, 5(2), 8895.

Coelho, P. M. F., e Costa, M. R. M. (2013). Entre o Game Educativo e a Obra Literária: a educação inserida nas novas mídias. EducaOnline: Educomunicação, educação e novas tecnologias, 7(3), 91111.

Eguia-gomez, J. L., Contreras-Espinosa, R. S., e Solano-Albajes, L. (2012). Os games digitais como um recurso cognitivo na aprendizagem: um estudo de caso. Revista E-scrita, 3(2), 120-133. Recuperado de: http://www.uniabeu.edu.br/publica/ index.php/RE/article/view/

Foucault, M. (1979). Microfísica do poder. Organização e tradução de Robert Machado. Rio de Janeiro: Edições Graal.

Fazgame. (2013a). Relatório de Avaliação do Projeto Piloto do FazGame (RAPPFazGame). Organizado por Carla Zeltzer e Antônio Flávio Oliveira Ramos. Rio de Janeiro: TECZELT. . (2013b). Projeto/Pesquisa com os Educadores (PPE). Organizado por Carla Zeltzer e Antônio Flávio Oliveira Ramos. Rio de Janeiro: TECZELT.

Gil, A. C. (2013). Como elaborar projetos de pesquisa. 7. ed. São Paulo: Atlas.
Hayes, E. (2007). Gendered identities at play: case studies of two women playing morrowind. Games and culture, 2(1), 2348.

Huizinga, J. (2013). Homo ludens: O jogo como elemento da cultura. Trad. João Paulo Monteiro. São Paulo: Perspectiva.

Kapp, K. (2012). The gamification oflearning and instruction: game-based methods and strategies for training and education. San Francisco: Pfeiffer.

Mattar, J. (2013). Games em educação: como os nativos digitais aprendem. 2 ed. São Paulo: Pearson Prentice Hall.

Papert, S. (2008). A máquina das crianças: repensando a escola na era da informática. Trad. Sandra Costa. Porto Alegre: Artmed.

Prensky, M. (2012). Aprendizagem baseada em jogos digitais. Trad. Eric Yamagute. São Paulo: Senac-SP.

. (2006). Don't bother me, Mom, $I^{\prime} m$ learning!: how computers and video games are preparing your kids for 21st century success and how you can help! St. Paul: Paragon House Publishers.

Ruiz, F. X. (2008). Juegos y videojuegos. Formas de vivencias narrativas. In Universidad de Vic. L'Homo Videoludens: entre la narrativa y la ludología. (17-51). Vic: Eumo Editorial.

Scheffler, I. (1973). Reason and Teaching. London: Routledge \& Kegan Paul.

Shwartz, G. (2014). Brinco, logo aprendo. Educação, videogames e moralidades pósmodernas. São Paulo: Paulus.

Vygotsky, L. S. (1978). Pensamiento y Lenguaje. Madrid: Paidos. .(1988).Linguagem, desenvolvimento $e$ aprendizagem. Tradução de Maria da Penha Villabobos. 5. ed. São Paulo: Icone; Editora da Universidade de São Paulo. 


\section{PERFIL ACADÊMICO E PROFISSIONAL DOS AUTORES}

Patrícia Margarida Farias Coelho. Doutora em Comunicação e Semiótica. Co-coordenadora do Grupo Interdisciplinario de Estudio sobre la Educación (Brasil/México) e Professora Titular do Programa de Mestrado Interdisciplinar em Ciências Humanas na Universidade de Santo Amaro. Linha de trabalho nas áreas de Comunicação, Semiótica, Educação e Novas tecnologias.

E-mail: patriciafariascoelho@gmail.com

\section{ENDEREÇO DO AUTOR}

Universidade de Santo Amaro

Campus II - Rua Isabel Schmidt, 349

Santo Amaro. São Paulo-SP/ Brasil

Marcos Rogério Martins Costa. Mestre em Letras e Psicanálise. Colaborador do Grupo Interdisciplinario de Estudio sobre la Educación (Brasil/México) e doutorando do Programa de Pós-Graduação em Semiótica e Linguística Geral da Universidade de São Paulo. Linha de trabalho nas áreas de Comunicação, Semiótica, Educação e Novas Tecnologias.

E-mail: marcosrmcosta15@gmail.com

\section{ENDEREÇO DO AUTOR}

Universidade de São Paulo

Departamento de Linguística.

Av. Prof. Luciano Gualberto, 403

Cidade Universitária. São Paulo - SP / Brasil

Fecha de recepción del artículo: 05/06/2015

Fecha de aceptación del artículo: 11/08/2015

\section{Como citar este artigo:}

Farias Coelho, P. M., y Martins Costa, M. R. (2016). Uma ferramenta digital que faz games educativos: o contexto brasileiro de ensino e aprendizagem. RIED. Revista Iberoamericana de Educación a Distancia, 19(2), pp. 53-70. doi: http:// dx.doi.org/10.5944/ried.19.2.14758 